\title{
An Empirical Analysis of Credit Card Customers' Overdue Risks for Medium- and Small-Sized Commercial Bank in Taiwan
}

\author{
Chia-Chi Lee ${ }^{1}$, Tyrone T. Lin ${ }^{2}$, Yi-Ting Chen ${ }^{3}$ \\ ${ }^{1}$ Department of Accounting Information, National Taipei College of Business, Taipei, Chinese Taipei; ${ }^{2}$ Department of International \\ Business, National Dong Hwa University, Hualien, Chinese Taipei. \\ Email: cclee@webmail.ntcb.edu.tw, tjlin@mail.ndhu.edu.tw, koibito99@gmail.com
}

Received April 22 ${ }^{\text {nd }}, 2011$; revised May 16 ${ }^{\text {th }}, 2011$; accepted May $18^{\text {th }}, 2011$.

\begin{abstract}
This paper constructs a multiple regression model to evaluate the overdue risk of credit card holders. The results can identify the factors influencing the credit card holders' overdue risk behavior in order to provide card issuing banks a decision-making reference in the investigation of credit card holders' related characteristics and the relationship quality between the credit card holders and the bank. In addition, the paper can also provide credit card issuing banks the practice reference of the application on risk management decision.
\end{abstract}

Keywords: Credit Card, Overdue Risk, Credit Card Holder, Credit Card Issuing Bank

\section{Introduction}

The rapid growth of the credit card market after the full liberalization results in the increase of people's dependence on credit cards [1]. For banks, the income derived from credit cards has changed from the past transaction amount fee of credit card payment into today's high revolving interest rate income of credit cards' loans. This change makes the credit card market become an important business sprint target of banks' earnings. Banks enjoy the generous income brought by credit card issuing, but should be careful about taking credit risk due to the over issuing problem in the credit card market [2].

Reference [3] points out that there is a concern about an increasing number of consumers may be unable to meet their future financial commitments. At the same time, credit providers are avidly seeking greater profits by enticing consumers to borrow more and more. Against this background, the issue of corporate social responsibility (CSR) in the Australian consumer credit industry is discussed. Therefore, in order to pursue banks' CSR and profits, the banking industry or related interest groups need to establish a complete risk control mechanism. In addition, for the consumers of the above-mentioned type, it is necessary to complete an in-depth study about the implementation of the relevant policies, regulations, and the application of business strategies so as to strengthen the sound operation of a financial system.

The paper explores the factors affecting the overdue credit card holders from two dimensions such as the personal characteristics of the credit card holder, the transaction relationship between the credit card holder and the case bank to identify the variables related to the dimensions of the empirical research. Through the use of the complete data established by the case bank, the paper can perform an overdue factor analysis. Different from most of the past studies which used only limited information publicly available as a research subject, the feature of the current research is to more specifically capture the potential factors affecting the credit card holder's overdue risk. The paper expects that the findings of the paper can provide banking executives a reference concerning deciding credit standards, loan amount, and criteria assessment in order to establish a complete risk control mechanism. The paper will also provide the government a reference about the future development of relevant financial regulations and policies.

\section{Hypotheses Development}

\subsection{Dimension of the Credit Card Holder's Personal Characteristics}

Whether a client has a higher level of occupation or not will affect the stability of his work. The occupations and 
companies with better welfare can usually more easily retain employees, whose work stability is also higher. The customers with a worse occupation will change work more often, and thus their stability decreases. Reference [4] uses the occupation classification as a variable and a decision tree to analyze it. The paper expects that the credit card holders with a higher level of occupation will have higher work stability and their probability of occurrence of credit card overdue risk will be lower. In that case, the credit card overdue amount is relatively low. Therefore, the hypothesis H1-1 is established as follows:

H1-1: The higher the credit card holder's occupation level is, the lower his credit card overdue amount will be.

Reference [5] points out that consumers' labor income will have an impact on the credit card overdue amount and the consideration of consumer loan credit focuses on whether customers have stable income and on the amount of revenue to determine their solvency. A customer with higher income stability and higher amount of revenue will have a lower overdue risk. Therefore, the paper expects that the amount of credit card holder's monthly income is negatively correlated with the credit card overdue amount. Thus, the hypothesis H1-2 is established as follows:

H1-2: The higher the credit card holder's monthly income is, the lower his credit card overdue amount will be.

The credit card business operates in coordination with banks' planning marketing activities to expect that credit card holders can use their cards more frequently after the application. Banks perform the analysis of consumers' credit card usage behavior in order to help the banking industry to provide comprehensive financial services and increase credit card holders' utilization rate [6]. However, if customers lack the ability of self-discipline and can not normally pay credit card accounts, the possibility of credit card overdue risk is relatively increased. Therefore, the paper expects that the credit card overdue amount of the credit card holders using their cards every month is relatively higher than that of the credit card holders not using their cards every month. Hence, the hypothesis H1-3 is established as follows:

H1-3: The credit card overdue amount of the card holder using his card every month is relatively higher than that of the credit card holder not using his card every month.

Credit card holders should deposit the amount of credit card bill into the bank designated account before the agreed credit card payment deadline [7]. The revolving credit users' will or ability of monthly fee is different from the credit card holders who pay the total amount of bill. If customers' payment begins to become unstable or the payment will is weak, the credit card overdue risk is increasing. Therefore, the paper expects that the credit card holder's payment will is negatively correlated with the credit card overdue amount. Therefore, the hypothesis H1-4 is established as follows:

H1-4: The higher the credit card holder's payment will is, the lower his credit card overdue amount will be.

\subsection{Dimension of the Transaction Relationship between the Credit Card Holder and the Bank}

The major purpose of using a credit card is to facilitate the payment. Because of the highly competitive credit card market, banks have lending money pressure and then allow credit card holders to withdraw cash with the revolving credit card interest rate under the credit limit. However, the customers who can have lower interest rate loans by normal ways rarely use credit cash [8]; this method is usually used by the credit card holders who are urgently in need of funds. Such customers are more active and diverse in the use of funds, but their credit card overdue risks are relatively increased. Therefore, the paper expects that the credit card holders using cash advance have relatively higher credit card overdue amounts than those not using cash advance. Thus, the hypothesis H2-1 is established as follows:

H2-1: The credit card holders using cash advance have relatively higher credit card overdue amounts than those not using cash advance.

Part of the credit card holders without the increase in income constantly use their credit cards as payment tools and begin to steadily accumulate the debts of revolving credit with high credit card interest rates [9]. The paper expects that the credit card holders who use the revolving credit interest will have relatively higher credit card overdue amounts compared with those who do not use it. Thus, the hypothesis H2-2 is established as follows:

H2-2: The credit card holders who use the revolving credit interest will have relatively higher credit card overdue amounts compared with those who do not use it.

For the credit card holders failing to pay off credit card accounts, the unpaid amount plus the revolving credit interest will be counted into the next bill. If the credit card holders continuously delay paying the total amount, the correspondent revolving credit interest will continuously to be charged. Thus, the increase of credit card principal and the corresponding revolving interest will make the credit card debtors be mired in the financial crisis. Reference [10] and Reference [11] find that the credit card holder's use of credit limit and the delays of credit card accounts significantly affect the increase of the credit card debt. Therefore, the paper expects that the higher the amount of revolving credit used by the credit card holder is, the higher the credit card overdue amount 
will be; they are positively correlated. Therefore, the hypothesis H2-3 is established as follows:

H2-3: The higher the amount of revolving credit used by the credit card holder is, the higher the credit card overdue amount will be.

The use of consumer finance credit tools is mainly to bring customers the convenience of using short-term working capital under emergency. If credit card holders use a large number of credit financing in short term, their fund leverage will tend to be too high. Reference [12] studies the financial situation of consumers and finds that the credit card loans have an absolute impact on the increase of consumer credit card debt which leads to a bankruptcy probability. The paper expects that the credit card holders having credit loans in other banks means that they have more shortage problems or financial difficulties in cash flows and their credit card overdue amounts will be relatively higher. Hence, the hypothesis H2-4 is established as follows:

H2-4: The credit card holders who have credit loans in other banks will have higher credit card overdue amounts compared with those who do not have credit loans in other banks.

Reference [13] uses the multiple criteria linear programming to propose a classification model and find that this model theory can deal with the credit card holders' behavior pattern of any class. They assess the behavior of the credit card holders pre-divided into four classes and perform the credit card management portfolio. They predict the key points of the credit card holders' consumer behavior to reduce the risk occurrence. The levy review officer of the case bank will composite score and give a risk level to a new credit card applicant in accordance with the customer's attributes. The credit card holder with a higher risk factor also has a higher overdue probability. The paper expects that there is a positive correlation between the credit card holder's risk coefficient and the credit card overdue amount. Thus, the hypothesis $\mathrm{H} 2-5$ is established as follows:

H2-5: The higher the credit card holder's risk coefficient set by the bank is, the higher the credit card overdue amount will be.

If customers possess longer bank credit cards, banks will be able to accumulate their personal credit ratings and then determine customers' loyalty to banks. Therefore, banks will have more negotiation space in determining whether they will give interest rate concessions to customers. Reference [14] points out that bank used to observe the historical information of loan applicants' accounts to predict their credit scoring. Therefore, the paper expects that the audit checks of the credit card holders having a longer transaction period with banks will be less rigorous compared with the customers of initial credit card application. Hence, the transaction period between the credit card holder and the bank is positively correlated with the credit card overdue amount. Therefore, the hypothesis H2-6 is established as follows:

H2-6: The longer the transaction period between the credit card holder and the bank is, the higher the credit card overdue amount will be.

Reference [15] finds that credit card holders having a good attitude of credit usage are more willing to maintain their credit quality. Reference [16] points out that the high ratio of used credit to the credit limits will increase the possibility of credit card overdue risk. The paper expects that the ratio of the credit card holder's used credit to the credit limit is positively correlated with the credit card overdue amount. Thus, the hypothesis H2-7 is established as follows:

H2-7: The higher the ratio of the used credit to the credit limit is, the higher the amount of the credit card overdue amount will be.

Reference [17] finds that the quality of bank auditors and the amount of issued credit have an absolute impact on whether the bank is able to select the appropriate client in accordance with conditions. If the credit card holder's credit limit issued by the bank is too high, it can potentially push the credit card holder to use too much amount of credit. Hence, the paper expects that the credit card's credit limit issued by the bank is positively correlated with the credit card overdue amount. Therefore, the hypothesis $\mathrm{H} 2-8$ is established as follows:

H2-8: The higher the credit card holder's credit limit issued by the bank is, the higher the credit card overdue amount will be.

\section{Methodology}

\subsection{Sample and Data Source}

The samples of the paper come from the credit card holders of a medium- and small-sized commercial bank from January 1998 to December 2006 for a total of nine years. The paper introduces a stratified random sampling way to choose 612 credit card holders which include 2 types of data segments: 439 normal credit card holders and 173 overdue credit card holders.

Normal credit card holders: it refers to the customers who pay the entire payable account or more than the minimum payable account before the current payment deadline. The payable account is the sum of current and previous unpaid credit card accounts, cash advance amount, or plus other payable accounts such as: interest on revolving credit, annual fees, cash advance fees, fees of report the loss, or the fees of accessing bill details. A total of 439 customers belong to the type of normal credit card holders. 
Overdue credit card holders: it refers to the customers who have not repaid the principal or interest yet for more than three months, or have prosecuted or dealt with the collaterals from the principal or accessory debtors even though not exceeding three months. The paper focuses on the occurred facts of customers' overdue risks. Therefore, the customers who have non-performing loans but become normal payment customers or transfer their credit loans to other banks after lending calls are still assigned to the type of overdue credit card holders.

\subsection{Regression Model}

According to the research hypotheses established in Section 2, the paper includes the control variables of overall economic environment in the regression model in order to control the influencing factors such as industrial characteristics, external environment, and economic climate on the credit card overdue amount. The empirical model (1) of the paper is developed as follows:

$$
A M T=\beta_{0}+\beta_{1} O C U P+\beta_{2} M R E V+\beta_{3} U C A R D+\beta_{4} W I L L+\beta_{5}
$$
$A D V N+\beta_{6} R E I N T+\beta_{7} R E I N T A M T+\beta_{8} B L O A N+\beta_{9} R I S K+\beta_{10}$ $P E R D+\beta_{11} R A T I O+\beta_{12} A P P R O V+\beta_{13} S C O R E+\beta_{14} U M E P+$ $\beta_{15} C G R O+e$

where the dependent variable $A M T$ is the credit card holder's actual overdue amount. On the independent variables, $O C U P$ is the credit card holder's occupation level, according to the occupational level in descending order, the paper sets 1 for the military staff and civil service workers; 2 for the business practitioners; 3 for the employees in the manufacturing industry; 4 for the workers in agriculture, forestry, fish, farming and the customers having no fixed working; $M R E V$ is the credit card holder's monthly income; $U C A R D$ is whether the credit card holder uses his credit card every month; WILL is the credit card holder's payment will, according to the payment will in descending order, the paper sets 1 for the full payable on time; 2 for the minimum payment due on schedule; 3 for the full payable after the deadline; 4 for the minimum payment due after the deadline. As to the default credit card holders; 5 is set for the first default and in arrears less than TWD10 thousand; 6 for the second default or spending money more than TWD10 thousand and less than TWD50 thousand; 7 for the third default or spending money more than TWD50 thousand and less than TWD200 thousand; $A D V N$ is whether the credit card holder uses cash advance; REINT is whether the credit card holder uses the revolving credit interest; REINTAMT is the amount of revolving credit used by the credit card holder; $B L O A N$ is whether the credit card holder has other banks' credit loans; RISK is the credit card holder's risk coefficient set by the case bank, according to the risk rating in ascending order, the paper sets 1) for the case bank's staff; 2) for the secured loan customers and excellent customers; 3 ) for the general customers; 4) for the customers holding an identity card; 5) for the customers of ad hoc promotion; 6) for the merchants staff of promotion cases; 7) for the customers from insurance agents' promotion cases; 8) for the customers of ad hoc promotion without auditing; 9) for the customers of high-risk; PERD is the transaction period between the credit card holder and the case bank; RATIO is the ratio of the used credit to the credit limit; $A P P R O V$ is the credit card holder's credit limit issued by the case bank. On the control variables, SCORE is the total score of monitoring indicators in Taiwan; UMEP is the unemployment rate; $C G R O$ is the annual growth rate of total credit card accounts. $\beta_{0}$ is the intercept; $\beta_{1} \ldots \beta_{15}$ are parameters of regression model; $e$ is the error term of regression model.

\section{Empirical Results and Discussions}

\subsection{Descriptive Statistic Results}

Table 1 shows the descriptive statistics for all variables. The mean value of $A M T$ is TWD32.34 thousand, the maximum is TWD353 thousand, and the minimum is 0 which indicates that it is a normal account without any overdue amount. As for the dimension of the credit card holder's personal characteristics, the mean value of OCUP is 3.067; the distribution of the sample object shows that the main credit card holders are the employees in the manufacturing industry. The mean value of $M R E V$ is TWD30.902 thousand, which indicates that most of the credit card holders are salaried workers; banks still prefer the customers having a fixed and stable source of income. The mean value of UCARD is 0.732 ; this reveals that more than half of the credit card holders are willing to use their credit cards as a monthly payment tool in the consumption. The mean value of WILL is 2.588, which means most of the credit card holders are willing to pay their credit card bills in time to maintain their good credit records.

For the dimension of the transaction relationship between the credit card holder and the bank, the mean value of $A D V N$ is 0.025 , which indicates that most of the credit card holders mainly use their credit cards as a payment tool, but not a credit loan tool. The mean value of REINT is 0.606 , which indicates most of the credit card holders will measure their capital needs and choose to pay the minimum payments while having difficulties in capital turnover in order to maintain a good credit rating and make flexible use of available funds. The mean value of REINTAMT is TWD40.827 thousand, which means that the credit card holders being unable to pay all the credit card bills will consider using the revolving credit interest; 
Table 1. Descriptive statistic.

\begin{tabular}{|c|c|c|c|c|c|c|c|}
\hline & Mean & Minimum & $25^{\text {th }} \%$ & $50^{\text {th }} \%$ (Median) & $75^{\text {th }} \%$ & Maximum & Std. deviation \\
\hline$A M T$ (Unit: 10 thousand TWD) & 3.234 & 0.000 & 0.000 & 0.000 & 2.900 & 35.300 & 6.548 \\
\hline OCUP & 3.067 & 1.000 & 3.000 & 3.000 & 4.000 & 4.000 & 0.791 \\
\hline MREV (Unit: thousand TWD) & 30.902 & 16.000 & 24.000 & 30.000 & 35.000 & 80.000 & 9.821 \\
\hline$W I L L$ & 2.588 & 1.000 & 1.000 & 2.000 & 4.000 & 7.000 & 2.011 \\
\hline$A D V N$ & 0.025 & 0.000 & 0.000 & 0.000 & 0.000 & 1.000 & 0.155 \\
\hline REINT & 0.606 & 0.000 & 0.000 & 1.000 & 1.000 & 1.000 & 0.489 \\
\hline REINTAMT (Unit: thousand TWD) & 40.827 & 0.000 & 0.000 & 7.950 & 66.000 & 317.000 & 62.270 \\
\hline$B L O A N$ & 0.183 & 0.000 & 0.000 & 0.000 & 0.000 & 1.000 & 0.387 \\
\hline RISK & 6.487 & 1.000 & 6.000 & 7.000 & 8.000 & 9.000 & 1.895 \\
\hline PERD (Unit: years) & 4.814 & 1.000 & 4.000 & 5.000 & 5.000 & 9.000 & 1.318 \\
\hline RATIO (Unit: \%) & 0.228 & 0.000 & 0.000 & 0.000 & 0.450 & 1.267 & 0.386 \\
\hline APPROV (Unit: 10 thousand TWD) & 12.270 & 2.000 & 8.000 & 12.000 & 15.000 & 35.000 & 6.380 \\
\hline SCORE & 22.032 & 12.500 & 19.500 & 19.500 & 27.000 & 30.500 & 5.227 \\
\hline UMEP (Unit: \%) & 4.757 & 2.690 & 4.570 & 4.990 & 5.170 & 5.170 & 0.639 \\
\hline CGRO (Unit: \%) & 17.063 & -3.490 & 11.490 & 13.495 & 26.140 & 27.815 & 6.585 \\
\hline
\end{tabular}

Notes: 1. The variable $A M T$ is the credit card holder's actual overdue amount; OCUP is the credit card holder's occupation level; $M R E V$ is the credit card holder's monthly income; UCARD is whether the credit card holder uses his credit card every month; WILL is the credit card holder's payment will; $A D V N$ is whether the credit card holder uses the cash advance; REINT is whether the credit card holder uses the revolving credit interest; REINTAMT is the amount of the revolving credit used by the credit card holder; BLOAN is whether the credit card holder has other banks' credit loans; RISK is the credit card holder's risk coefficient set by the case bank; $P E R D$ is the transaction period between the credit card holder and the case bank; $R A T I O$ is the ratio of the used credit to the credit limit; APPROV is the credit card holder's credit limit issued by the case bank; SCORE is the total score of monitoring indicators in Taiwan; UMEP is the unemployment rate; $C G R O$ is the annual growth rate of total credit card accounts. 2. The total observations are 612 records.

the amortization of principal and interest can reduce debtors' payment stress. The mean value of $B L O A N$ is 0.183 ; it means that most of the credit card holders do not have other banks' credit loans. The mean value of RISK is 6.487; it means that most of the customers are concentrated in the merchants' staff of promotion cases and the customers from insurance agents' promotion cases. The mean value of PERD is 4.814 years; it means that the credit card holders hold their credit cards for about five years. The mean value of RATIO is $0.228 \%$; it means that the customers who use the revolving credit interest will not excessively expand their credit. The mean value of $A P P R O V$ is TWD122.7 thousand, which shows that the assessment criteria of the customer's credit limit is based on his credit capacity.

As for the control variables, the mean value of SCORE is 22.032; it means that the average Taiwanese economy is in the state of moderate development. The mean value of $U M E P$ is $4.757 \%$; this indicates that during the sample period, the unemployment rate increased from 1998 and decreased in 2006. The mean value of $C G R O$ is $17.063 \%$; this indicates that the average annual growth rate of total credit card accounts increased slightly since 1998 and showed a huge decline in 2005.

\subsection{Regression Results}

Table 2 shows the regression results of credit card overdue amount. Firstly, Panel A is the ANOVA analysis of the regression model. The regression model shows good fitness, reaching a significant level $(F$-statistic $=264.483$, $p$ value $=0.000)$, and $R^{2}=0.869$, Adj. $R^{2}=0.866$; therefore, the explanatory ability of the model for independent and control variables are all superior to $80 \%$. In addition, the variance inflation factor (VIF) test of all independent and control variables are all inferior to 10 , which means that there is no such thing as a high degree of collinearity problem between variables.

Panel B is the regression analysis results. As to the dimension of the credit card holder's personal characteristics, $O C U P$ and $A M T$ are significantly positively correlated ( $p$ value $=0.009$ ), reaching the statistically significant level of $1 \%$. This is consistent with the expected direction of hypothesis; thus, the hypothesis H1-1 is supported. It means that when the credit card holder's occupation belongs to the military staff and civil service workers (category 1), the overdue amount will be lower; on the other hand, when the credit card holder belongs to the workers in agriculture, forestry, fish, farming, or the customers having no fixed working (category 4), the overdue amount will be higher. MREV and $A M T$ are insignificantly negatively correlated; even though it is consistent with the expected direction of hypothesis, it does not reach a statistically significant level. Therefore, the hypothesis H1-2 is not supported. However, the result of the variable can still reveal that when the credit card holder's has higher monthly income, his solvency will be more stable and the overdue amount will be relatively lower. $U C A R D$ and $A M T$ are significantly positively correlated ( $p$ value $=0.000)$, reaching the statistically significant level of $1 \%$. This is consistent with the expected direction of hypothesis; thus, the hypothesis H1-3 is supported. It means that when the credit card holder uses his credit card every month, the overdue amount will be higher. WILL and $A M T$ are significantly positively 
Table 2. Regression results of credit card overdue amount.

Panel A: ANOVA analysis
\begin{tabular}{lccccccc}
\hline & Sum of squares & $\mathrm{df}$ & Mean square & $F$-statistic & $\operatorname{Prob}(F$-statistic $)$ & $R^{2}$ & $\operatorname{Adj} . R^{2}$ \\
\hline Regression & $22,776.882$ & 15.000 & $1,518.459$ & $264.483^{* * *}$ & 0.000 & 0.869 & 0.866 \\
Residual & $3,421.778$ & 596.000 & 5.741 & & & & \\
Total & $26,198.659$ & 611.000 & & & & & \\
\hline
\end{tabular}

Panel B: Regression results

\begin{tabular}{|c|c|c|c|c|c|c|}
\hline \multirow{2}{*}{ Variables } & \multirow{2}{*}{ Predicted sign } & \multicolumn{5}{|c|}{ Total sample $(N=612)$} \\
\hline & & Coefficient & Std. error & $t$ value & $p$ value (one-tailed) & VIF \\
\hline Intercept & & -5.652 & 2.273 & -2.487 & $0.007 * * *$ & \\
\hline$O C U P$ & + & 0.320 & 0.136 & 2.362 & $0.009 * * *$ & 1.225 \\
\hline$M R E V$ & - & -0.011 & 0.010 & -1.073 & 0.142 & 1.089 \\
\hline$U C A R D$ & + & 2.633 & 0.590 & 4.463 & $0.000^{* * *}$ & 7.282 \\
\hline$W I L L$ & + & 1.008 & 0.134 & 7.510 & $0.000 * * *$ & 7.758 \\
\hline$A D V N$ & + & 0.386 & 0.648 & 0.596 & 0.276 & 1.070 \\
\hline REINT & + & -2.303 & 0.326 & -7.063 & $0.000 * * *$ & 2.706 \\
\hline REINTAMT & + & 0.017 & 0.003 & 6.924 & $0.000 * * *$ & 2.621 \\
\hline$B L O A N$ & + & 0.768 & 0.466 & 1.647 & $0.050 * *$ & 3.468 \\
\hline RISK & + & -0.046 & 0.055 & -0.840 & 0.201 & 1.161 \\
\hline PERD & + & 0.033 & 0.150 & 0.222 & 0.412 & 4.140 \\
\hline RATIO & + & 12.401 & 0.631 & 19.656 & $0.000 * * *$ & 6.313 \\
\hline$A P P R O V$ & + & 0.263 & 0.017 & 15.111 & $0.000^{* * *}$ & 1.315 \\
\hline SCORE & & -0.022 & 0.040 & -0.560 & 0.288 & 4.637 \\
\hline$U M E P$ & & -0.266 & 0.215 & -1.237 & 0.108 & 2.004 \\
\hline$C G R O$ & & 0.005 & 0.022 & 0.216 & 0.415 & 2.169 \\
\hline
\end{tabular}

correlated ( $p$ value $=0.000)$, reaching the statistically significant level of $1 \%$. This is consistent with the expected direction of hypothesis; thus, the hypothesis H1-4 is supported. It means that when the credit card holder has higher payment will, the overdue amount will be lower.

As for the dimension of the transaction relationship between the credit card holder and the bank, $A D V N$ and $A M T$ are insignificantly positively correlated; even though it is consistent with the expected direction of hypothesis, it does not reach a statistically significant level. Therefore, the hypothesis H2-1 is not supported. However, the result of the variable can still reveal that the credit card holder having difficulties in capital turnover starts to use the cash advance; therefore, the overdue amount will be higher. REINT and $A M T$ are significantly negatively correlated ( $p$ value $=0.000$ ), reaching the statistically significant level of $1 \%$. That is, the credit card holders using the revolving credit interest have lower overdue loan amounts; those who do not use the revolving credit interest have higher overdue loan amounts. It is not consistent with the expected direction of hypothesis, thus, the hypothesis H2-2 is not supported. The further observations from the practice show that even though the credit card holders can not totally pay their credit card debts in order to maintain the good credit status, they will at least choose to pay the minimum payments due; it is deemed that the credit card holders are willing to be responsible for their credit card debts. Therefore, the customers who pay attention to their own credit rating will have lower overdue amounts. REINTAMT and AMT are significantly positively correlated $(p$ value $=0.000$ ), reaching the statistically significant level of $1 \%$. This is consistent with the expected direction of hypothesis; thus, the hypothesis H2-3 is supported. It means that when the credit card holder's revolving credit amount gradually increases, the overdue amount will be higher. BLOAN and $A M T$ are significantly positively correlated ( $p$ value $=0.050$ ), reaching the statistically significant level of $5 \%$. This is consistent with the expected direction of hypothesis; thus, the hypothesis H2-4 is supported. It means that when the credit card holder has other banks' credit loans, the overdue amount will be higher.

RISK and $A M T$ are insignificantly negatively correlated and it is not consistent with the expected direction of hypothesis; thus, the hypothesis H2-5 is not supported. The reason for the insignificance is probably due to the fact that the risk coefficient is set in accordance with the 
credit card holder's occupation and the acquisition channel. In practice, even though the bank sets the credit card holder to a high risk category, if the credit card holder is willing to maintain a good credit status and pay the monthly credit card payments on time, it will not result in an increase in the amount of overdue loans. PERD and $A M T$ are insignificantly positively correlated; even though it is consistent with the expected direction, it does not reach the statistically significant level. Thus, the hypothesis H2-6 is not supported. RATIO and AMT are significantly positively correlated ( $p$ value $=0.000$ ), reaching the statistically significant level of $1 \%$. It is consistent with the expected direction of hypothesis; thus, the hypothesis H2-7 is supported. It means that the higher the ratio of used credit to the credit limit is, the higher the overdue amount will be. APPROV and $A M T$ are significantly positively correlated ( $p$ value $=0.000$ ), reaching the statistically significant level of $1 \%$. It is consistent with the expected direction of hypothesis; thus, the hypothesis H2-8 is supported. It means that the higher the credit card holder's credit limit issued by the bank is, the higher the overdue amount will be.

Even though the three macroeconomic control variables, SCORE, UMEP, CGRO do not have significant impacts on the overdue amount, the results of these three variables can still indicate that when the economy in Taiwan is good, the overdue amount will be lower; when the unemployment rate is higher, the customers using credit cards more conservatively will not increase the overdue amount. When the annual growth rate of total credit card accounts increases, it means that customers use credit cards more frequently; therefore, the overdue amount will be higher.

\section{Conclusions and Suggestions}

The paper makes the following recommendations about the credit amount of credit card lending for the banking industry and management decision-making units: 1) the recommendation to the card issuing banks' planning unit: it is suggested that before the issuance of credit cards, the ad hoc planning unit's credit card promotions should engage the consumer market segmentation and consider the potential customers of professional levels as the choice of target customers; 2) the recommendation to the card issuing banks' credit approval unit: it is suggested that after improving plans, the planning unit's credit reviewer and loan approval staff should rigorously control applicants' credit conditions; while examining their provided written credit reports, the banks should refer to the purpose of customers' consumption and use of a credit card and customers' financial status in order to perform the detailed assessment of applicants' future ability and willingness to repay their debts; 3) the recommendation to the card issuing banks' audit unit: the audit unit is suggested to implement the rigorous internal control to ensure that no fraud circumstances will happen. It is also suggested to appropriately adjust the lending regulations of current financial situation under the present social economy situation in order to avoid the outdated regulatory information and prevent the front-line workers from facing the dilemma of not immediately dealing with a contingency or emergency; 4) the recommendation to the card issuing banks' highest decision-making unit: the business development should be based on the concept of sustainability and stability. The operating environment of the financial industry is highly changeable; it repeatedly tests the highest decision-making unit's wisdom and common sense. If banks only seek temporary profits and hurt business foundation, it will be worth the candle. In the pursuit of return on equity, it should be more pragmatic to face the potential change of perspective, but also to take into account the social responsibility in order to reduce the generation of business cost and social cost.

\section{Acknowledgements}

The authors would like to thank the National Science Council of the Republic of China, Taiwan for financially supporting this research under Contract No. NSC 98-2410-H-259-010-MY3 and NSC 99-2410-H-141007-MY2.

\section{REFERENCES}

[1] K. J. White, "Consumer Choice and Use of Bank Credit Cards: A Model and Cross-Section Results,” Journal of Consumer Research, Vol. 2, No. 1, 1975, pp. 10-18. doi:10.1086/208611

[2] M. Howard, "Shifting Risk and Fixing Blame: The Vexing Problem of Credit Card Obligations in Bankruptcy," The American Bankruptcy Law Journal, Vol. 75, No. 1, 2001, pp. 63-143.

[3] M. Griffiths, "Consumer Debt in Australia: Why Banks will Not Turn Their Backs on Profit," International Journal of Consumer Studies, Vol. 31, No. 3, 2007, pp. 230-236. doi:10.1111/j.1470-6431.2006.00524.x

[4] L. L. Gan, R. C. Maysami and H. C. Koh, "Singapore Credit Cardholders: Ownership, Usage Patterns, and Perceptions,” Journal of Services Marketing, Vol. 22, No. 4, 2008, pp. 267-279. doi:10.1108/08876040810881678

[5] P. Lopes, "Credit Card Debt and Default over the Life Cycle,” Journal of Money, Credit and Banking, Vol. 40, No. 4, 2008, pp. 769-790. doi:10.1111/j.1538-4616.2008.00135.x

[6] A. Kara, E. Kaynak and O. Kucukemiroglu, “An Empirical Investigation of US Credit Card Users: Card Choice and Usage Behavior," International Business Review, Vol. 5, No. 2, 1996, pp. 209-230. doi:10.1016/0969-5931(96)00006-6 
[7] C. Sprenger and J. Stavins, "Credit Card Debt and Payment Use," Working Paper, Federal Reserve Bank of Boston, 2008.

[8] E. C. Lawrence and G. Elliehausen, "A Comparative Analysis of Payday Loan Customers," Contemporary Economic Policy, Vol. 26, No. 2, 2008, pp. 299-316. doi:10.1111/j.1465-7287.2007.00068.x

[9] R. H. Scott, "Credit Card Use and Abuse: A Veblenian Analysis,” Journal of Economic Issues, Vol. 41, No. 2, 2007, pp. 567-574.

[10] C. R. Hayhoe, L. Leach and P. R. Turner, "Discriminating the Number of Credit Cards Held by College Students Using Credit and Money Attitudes," Journal of Economic Psychology, Vol. 20, No. 6, 1999, pp. 643-656. doi:10.1016/S0167-4870(99)00028-8

[11] T. Grieb, C. Hegji and S. T. Jones, "Macroeconomic Factors, Consumer Behavior, and Bankcard Default Rates," Journal of Economics and Finance, Vol. 25, No. 3, 2001, pp. 316-327. doi:10.1007/BF02745892

[12] J. Stavins, "Credit Card Borrowing, Delinquency, and Personal Bankruptcy,” New England Economic Review,
July/August, 2000, pp. 15-30.

[13] G. Kou, Y. Peng, Y. Shi, M. Wise and W. Xu, "Discovering Credit Cardholders' Behavior by Multiple Criteria Linear Programming," Annals of Operations Research, Vol. 135, No. 1, 2005, pp. 261-274. doi:10.1007/s10479-005-6245-5

[14] J. C. Courtless, “Trends in Consumer Credit," Family Economics Review, Vol. 6, No. 3, 1993, pp. 8-17.

[15] Y. W. Chien and S. A. Devaney, "The Effects of Credit Attitude and Socioeconomic Factors on Credit Card and Installment Debt," The Journal of Consumer Affairs, Vol. 35, No. 1, 2001, pp. 162-179. doi:10.1111/j.1745-6606.2001.tb00107.x

[16] D. B. Gross and N. S. Souleles, “An Empirical Analysis of Personal Bankruptcy and Delinquency," Review of Financial Studies, Vol. 15, No. 1, 2002, pp. 319-347. doi:10.1093/rfs/15.1.319

[17] S. Dey and G. E. Mumy, "Determinants of Borrowing Limits on Credit Cards,” Working Paper, November 22, 2009. 